\title{
EVALUATION OF ADHESION BETWEEN ADHESIVE COATING AND STEEL SUBSTRATE BY ULTRASONIC METHOD
}

\author{
D. Ulbrich*, J. Selech ${ }^{* *}$, D. Romek ${ }^{* * *}$, K. Włodarczyk ${ }^{\dagger}$, J. Kowalczyk $^{\ddagger}$, \\ J. Marcinkiewicz ${ }^{\ddagger \dagger}, \dot{Z}$. Staszak ${ }^{\S}$
}

\begin{abstract}
In the article the non-destructive method of an evaluation of adhesion between adhesive coating and steel substrate is presented. The adhesion was calculated on the basis of ultrasonic measurement of wave propagating on the border of the adhesive connection. Measurements were performed in nine deterimned points before and after application of car putty coating. In each point, 30 measurements of parameters of ultrasonic wave were conducted. The height of the pulses reflected from the bottom of the steel sheet and then from the interface between the coating and the steel substrate was controlled. The average value of the reflection coefficient was on the level around 0.5. On the basis of the reflection, the coefficients can be estimated adhesion of the coating to the substrate, expressed in MPa, which is about 3.5 to $7.5 \mathrm{MPa}$. The next step in research is to calculate reflection coefficient value for surfaces prepared in a different way and for different adhesive coatings.
\end{abstract}

Keywords: adhesion, coating, ultrasound, steel substrate

\section{Introduction}

Bonds between surfaces and coating are widely used in construction of modern machines and motor vehicles. Adherence is referred as adhesion of the coating to the substrate. It depends mainly on the method of preparing the surface of the substrate as well as the factors that affect during the application of the coating. In many articles, also (Adams, 2005) some theories (i.e. mechanical theory) and hypotheses about adhesion were presented.

There are many non-destructive techniques used for adhesive joints testing (Adams et al., 1997). The most popular methods are the ultrasonic, radiographic, thermographic and holographic method. Ultrasonic testing of adhesive joints is carried out using surface, longitudinal, transverse, Lamba and Stoneley waves. Depending on which of these waves is used in the research an appropriate measuring system should be used allowing to detect quality of adhesion (Drewry et al., 2009). To evaluate adhesion between coating and substrate the reflection coefficient is determined (Biwa et al., 2005). This coefficient

Assoc. Prof. Dariusz Ulbrich, PhD, DSc: Institute of Machines and Motor Vehicles, Poznan University of Tecnology, 5 M. Skłodowska-Curie Square; 60-965, Poznan; PL, dariusz.ulbrich@put.poznan.pl

** Assoc. Prof. Jarosław Selech, PhD, DSc.: Institute of Machines and Motor Vehicles, Poznan University of Tecnology, 5 M. Skłodowska-Curie Square; 60-965, Poznan; PL, jarosław.selech@put.poznan.pl

*** Dawid Romek, MSc.: Institute of Machines and Motor Vehicles, Poznan University of Tecnology, 5 M. Skłodowska-Curie Square; 60-965, Poznan; PL, dawid.e.romek@doctorate.put.poznan.pl

$\dagger \quad$ Assoc. Prof. Konrad Włodarczyk, PhD, DSc.: Institute of Machines and Motor Vehicles, Poznan University of Tecnology, 5 M. Skłodowska-Curie Square; 60-965, Poznan; PL, konrad.wlodarczyk@put.poznan.pl

$\$ \quad$ Assoc. Prof. Jakub Kowalczyk, PhD, DSc.: Institute of Machines and Motor Vehicles, Poznan University of Tecnology, 5 M. Skłodowska-Curie Square; 60-965, Poznan; PL, jakub.kowalczyk@put.poznan.pl

\# Assoc. Jacek Marcinkiewicz, MSc.: Institute of Machines and Motor Vehicles, Poznan University of Tecnology, 5 M

$\S$ Assoc. Prof. Żaneta Staszak, PhD, DSc.: Institute of Machines and Motor Vehicles, Poznan University of Tecnology, 5 M. Skłodowska-Curie Square; 60-965, Poznan; PL, zaneta.staszak@put.poznan.pl 
can be calculated in some ways. One of them was presented in this article but some authors use reformulation of this parameter to identify adhesion and quality of the adhesive joint (Chen et al., 2012).

\section{Methods and research}

During research steel substrate (deep-drawing steel used for motor vehicles body), car putty coating as well as ultrasonic flaw detector with high frequency ultrasonic transducer were used. The first step of the experiment was to prepare surface of the steel sample. The surface was grinded manually (by hand) by sandpaper marked 40. Then ultrasonic measurements before applying the coating were performed. Ultrasonic testing was carried out from the side on which the coating was not applied. The measurements were conducted using a template that kept the same measuring point. Nine measurement points spread over the entire surface where the coating was applied and 30 measurements were made at each nine point before and after the coating was applied. Sample with applied coating and ultrasonic transducer during the measurement were shown in the Fig. 1.

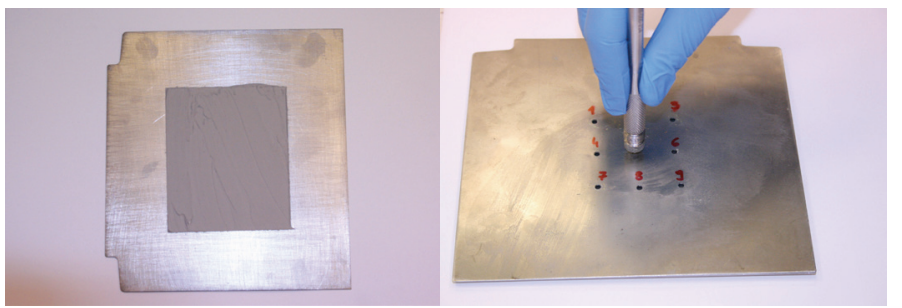

Fig. 1: Sample with car putty coating (left picture) and ultrasonic transducer during measurements of echoes height (right picture).

Ultrasonic measurements were carried out at constant ultrasonic flaw detector settings (gain of the pulse, ultrasonic wave velocity, range of observation, etc.). The height of first and second echo before and after application of the coating was measured. Some results (10 from 30 measurements) for one of the nine points are shown in Tab. 1.

Tab. 1: Examples of echoes height measured for one of the nine points before and after the coating was applied.

\begin{tabular}{ccccc}
\hline Measurement & \multicolumn{2}{c}{$\begin{array}{c}\text { The height of echoes before } \\
\text { applying the coating }\end{array}$} & \multicolumn{2}{c}{$\begin{array}{c}\text { The height of echoes after } \\
\text { applying the coating }\end{array}$} \\
\cline { 2 - 5 } & $\mathbf{1}$ echo & $\mathbf{2}$ echo & $\mathbf{1}$ echo & $\mathbf{2}$ echo \\
\hline 1 & 94 & 76 & 57 & 25 \\
\hline 2 & 96 & 77 & 56 & 24 \\
\hline 3 & 90 & 63 & 53 & 24 \\
\hline 4 & 94 & 74 & 55 & 24 \\
\hline 5 & 93 & 75 & 56 & 25 \\
\hline 6 & 98 & 79 & 58 & 23 \\
\hline 7 & 98 & 80 & 58 & 25 \\
\hline 8 & 98 & 80 & 60 & 23 \\
\hline 9 & 94 & 78 & 56 & 22 \\
\hline 10 & 96 & 78 & 58 & \\
\hline
\end{tabular}

On the base of echoes height the reflection coefficient was calculated (Jósko, 2002):

$$
\left|\mathrm{r}_{21}\right|=10^{-\frac{\Delta \mathrm{W}}{20}}
$$

$\mathrm{r}_{21}$ - reflection coefficient, 
$\Delta \mathrm{W}$ - drop in pulses height, expressed in decibels (difference between first echo before and after application of the coating).

The reflection coefficient is non-destructive parameter that is the measure of adherence of the coating to the surface and consequently the quality of the adhesive bond. The reflection coefficient assumes values in the range from 0 to 1 . Lower value of this coefficient is equal better adhesion of the coating to the substrate. The average value of reflection coefficient for nine series was presented in Fig. 2 and the distribution of adhesion across the entire measurement area was presented in Fig. 3.

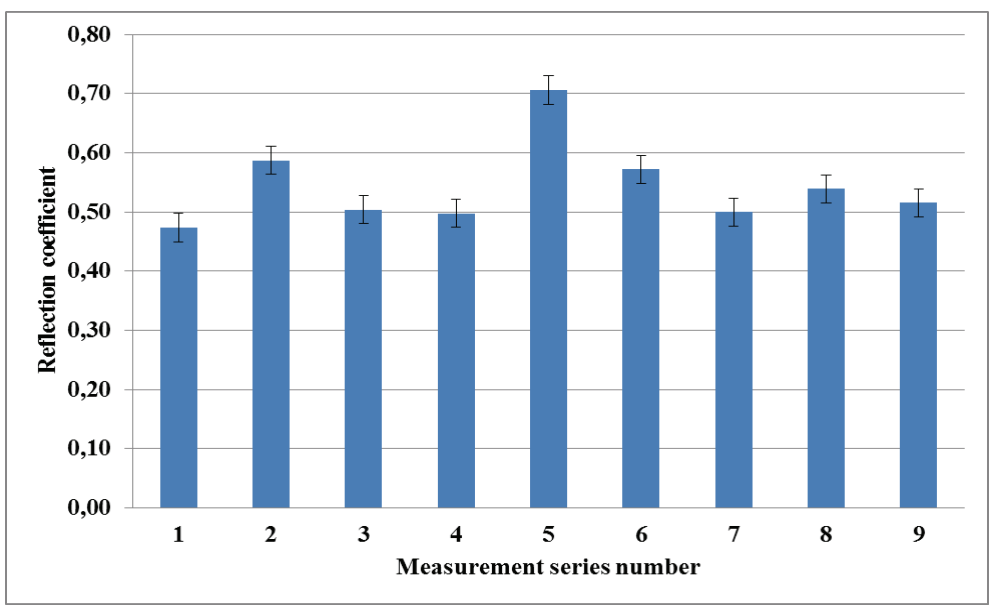

Fig. 2: Average reflection coefficient calculated in 9 measuring points.



Fig. 3: Reflection coefficient distribution on the entire surface of the connection.

To evaluate adhesion between coating and steel substrate the correlation of reflection coefficient and adhesion expressed in MPa should be done. One of the authors (Ulbrich, 2015) has defined the connection between the reflection coefficient and the mechanical adhesion of the car putty coating to the surface (Fig. 4). The reflection coefficient was determined for surface manual preparation by sandpaper marked 80. Therefore, only the value of mechanical adhesion has been estimated. To accurately determination of the value of this adhesion it is necessary to perform correlation tests for the substrate prepared as in the case of the sample described in the article. Based on the relationship shown in the Fig. 4 it can be estimated the level of adhesion of the coating to the substrate which is in the range from around 3.5 to $7.5 \mathrm{MPa}$.

Estimating the adhesion of the coating to the substrate at the exploitation stage is important from the point of view of its durability and meeting the requirements of protecting the substrate against corrosion. The authors believe that the developed technique for assessing the adhesion of the coating to the substrate may be part of various systems for maintenance and diagnostics of technical objects such as system presented in Gill A. (2017). 


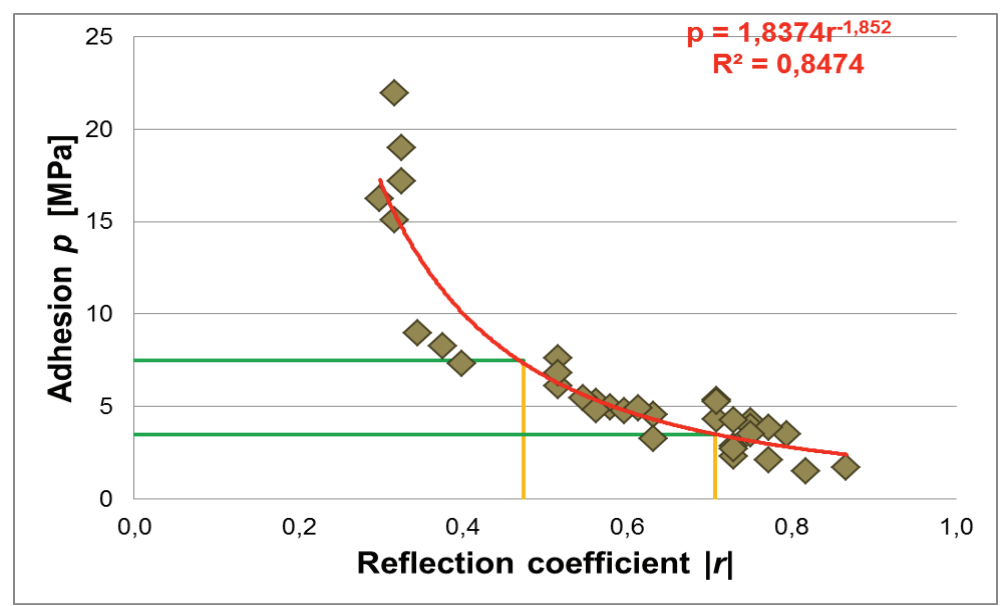

Fig. 4: Reflection coefficient values correlated with adhesion.

\section{Conclusions}

On the basis of the performed experiment the following conclusions can be drawn:

- the reflection coefficient can be used for non-destructive determination of adhesion of adhesive coatings to steel substrates especially at the stage of manufacturing such a joint as well as its exploitation,

- determined reflection coefficient values are on the level from 0.474 to 0.706 which corresponds to the adhesion of the coating to the substrate in the range 3.5 to $7.5 \mathrm{MPa}$,

- for most of the nine measuring points the average value of the reflection coefficient reaches the value of about 0.5 and only in one case this average value is much higher and amounts over 0.7 , which may indicate a worse adhesion of the coating to the steel substrate in this place,

- to avoid differences in reflection coefficient values as well as adhesion of the coating to the substrate instead of manual surface preparation grinding with machines that ensure constant pressure force to the surface should be used.

In the future reflection coefficient for different ways of surface preparation should be determined. Also, the different types of adhesive coating should be used for preparation adhesive bond (e.g. car putty coating with fiberglass, metallic polymers coatings, sealants and adhesives).

\section{Acknowledgements}

The research was supported by statutory resources appropriated to Institute of Machines and Motor Vehicles, Poznan University of Technology as "The Grant for Young Researchers" No. 05/51/DSMK/3530 and the Grant No. 05/51/DSPB/3551.

\section{References}

Adams, R. D. (2005) Adhesive bonding Science, technology and application. Woodhead Publishing Limited.

Adams, R.D. and Drinkwater, B.W. (1997) Nondestructive testing of adhesively-bonded joints. NDT\&E International, 30, 2, pp. 93-98.

Biwa, S., Suzuki, A. and Ohno, M. (2005) Evaluation of interface wave velocity, reflection coefficients and interfacial stiffnesses of contacting surfaces. Ultrasonics, 43, pp. 495-502.

Chen, J., Bai, X., Yang, K. and Ju, B.F. (2012) The computations of reflection coefficient of multilayered structure based on the reformulation of Thomson-Haskel method. Ultrasonics, 52, pp. 1019-1023.

Drewry, M.A., Smith, R.A., Phang, A.P., Yan, D., Wilcox, P. and Roach, D.P. (2009) Ultrasonic techniques for detection of weak adhesion. Materials Evaluation, 19, pp. 1048-1058.

Gill, A. (2017) Optimisation of the technical object maintenance system taking account of risk analysis results. Eksploatacja i Niezawodnosc-Maintenance and Reliability, 19, 3, pp. 420-431

Jósko, M. (2002) Methodological aspects of the adhesion of regenerative coatings by ultrasound. Poznan (in Polish).

Ulbrich, D. (2015) Evaluation of coating adhesion by ultrasonic method. PhD thesis, Poznan (in Polish). 